\title{
ALTERAÇÃO CURRICULAR DO CURSO DE BIBLIOTECONOMIA DA UNIVERSIDADE DO ESTADO DE SANTA CATARINA - UDESC
}

\author{
Maria Lourdes Blatt OHIRA \\ Noêmia Schoffen PRADO \\ Gisela EGGERT \\ Ivonir Terezinha HENRIQUE \\ Maria Emilia Ganzarolli MARTINS e \\ Maria de Jesus NASCIMENTO'
}

\section{RESUMO}

Apresenta a proposta curricular do Curso de Biblioteconomia da Universidade do Estado de Santa Catarina - UDESC, no que tange aos aspectos relacionados com a Biblioteconomia catarinense, com a literatura sobre o Moderno Profissional da Informação e com os estudos de compatibilização curricular realizados no Brasil e em âmbito do Mercosul.

Palavras-chave: Estrutura Curricular; Curso de Biblioteconomia.

\begin{abstract}
This paper presents the Universidade do Estado de Santa Catarina (UDESC) 's Library Studies curriculum and discusses questions related to the modern information professional education. Presents also curricula compatibility between Brazil and the Mercosul countries.
\end{abstract}

Key words: Library Schoool Curriculum.

\section{INTRODUÇÃO}

O Departamento de Biblioteconomia e Documentação da Universidade do Estado de Santa Catarina - UDESC acompanhou eventos e estudos relativos a situação e avaliação dos cursos de Biblioteconomia, em âmbito internacional, nacional, regional e local. Um dos resultados dessas avaliações, se refere ao termo "Biblioteconomia", que deriva do termo biblioteca, composto por biblio (livro), e theke (caixa), formação esta que evidencia a concepção de biblioteca enquanto caixa de livros. Talvez por esse fato, o grande público associe o termo "Biblioteconomia" aos livros, à biblioteca, às técnicas em- pregadas e aos serviços prestados no âmbito desta instituição.

Todavia, já há algumas décadas, a área vem trabalhando com a informação, independentemente de seu suporte físico e da instituição que a possui. Nosso entendimento é de que esse nome teria que representar as mudanças que vem ocorrendo na área e no mercado de trabalho, conseqüência da globalização e da incorporação das novas tecnologias da informação. Considerando-se que, a Legislação Bibliotecária vigente, atribui a esse profissional o título de Bibliotecário, torna-se necessário manter

1. Professoras do Curso de Biblioteconomia da Universidade do Estado de Santa Catarina (UDESC). 
esse mesmo título, Visando adequá-lo ao momento atual, propõe-se, neste momento, a criação da Habilitação em Gestão da Informação. Novas habilitações deverão ser implantadas ao longo do tempo, de acordo com a demanda do mercado de trabalho, permitindo assim que as necessidades sejam atendidas.

Tendo em vista que ainda encontram-se em estudo as Diretrizes Curriculares Brasileiras para a área de Ciência da Informação, que engloba os cursos de Biblioteconomia, Arquivologia e Museologia, a proposta de alteração curricular para o Curso de Biblioteconomia - Habilitação em Gestão da Informação da Universidade do Estado de Santa Catarina - UDESC atende as exigências legais para a estruturação curricular determinadas pelos seguintes documentos:

1. Resolução 08 de 29 de outubro de 1982, do Conselho Federal de Educação que estabelece as matérias para o currículo mínimo do Curso de Biblioteconomia, $e$

2. Proposta de Diretrizes Curriculares para os Cursos de Biblioteconomia do MEC, que estão em discussão no Conselho Nacional de Educação - CNE.

\section{BIBLIOTECONOMIA EM SANTA CATARINA}

O Curso de Biblioteconomia do Centro de Ciências da Educação, da Universidade do Estado de Santa Catarina - FAED/UDESC, foi aprovado através do parecer 435/73 e implantado em 1974. Desde a sua criação, são ofertadas, anualmente, 40 vagas via vestibular. Teve a sua primeira reformulação curricular no ano de 1985.

Ao longo desses anos, o Departamento de Biblioteconomia e Documentação tem realizado inúmeras pesquisas envolvendo o bibliotecário no exercício da sua profissão, sendo levantados dados sobre o mercado de trabalho, necessidade de educação continuada, qualificação dos profissionais, análise dos pedidos de cancelamento e/ou licença temporária junto ao Conselho Regional de Biblioteconomia - $\mathrm{CRB} / 14$, número de formandos no período e índice de evasão do Curso dentre outros
(OHIRA et al., 1997); (PROSDÓCIMO, 1999); (BANDEIRA, 1999) e (EGGERT, 2000). Através dos resultados destas pesquisas, foi possível detectar o nível de desenvolvimento e absorção dos profissionais da informação pelo mercado de trabalho catarinense concluindo-se que:

- As Bibliotecas Universitárias e as Bibliotecas Especializadas apresentam-se como um mercado consolidado e em expansão frente ao crescimento vertiginoso do número de instituições de ensino superior no Estado de Santa Catarina, e a consequente criação e expansão dos Institutos de Pesquisas, Centros de Informação Científica e Tecnológica;

- As Bibliotecas Escolares, a partir da instituição da Rede de Bibliotecas Escolares do município de Florianópolis, mostrou a necessidade de expansão desse mercado para as Bibliotecas Escolares da Rede Pública Estadual;

- Nas Bibliotecas Públicas a pouca presença do profissional da informação é sentida e espera-se que, com o Programa "Uma Biblioteca em cada Município" em implantação pelo Ministério da Cultura, favoreça a democratização e acesso a informação ao cidadão catarinense;

- Nas indústrias catarinenses o profissional da informação é ainda desconhecido e/ou percebido como um Bibliotecário Tradicional. A informação é atualmente elemento essencial na empresa moderna e este segmento requer um profissional da informação que tenha características de empreendedor;

- Para os profissionais que atuam em Arquivos Públicos e Empresariais, o curso de Biblioteconomia oferece noções básicas para gestão de documentos, sendo necessário que o aperfeiçoamento e a especialização sejam buscadas após o Curso de Graduação.

Lembrando que a Sociedade de Informação constitui-se numa nova era em que a informação flui a velocidades e em quantidades surpreendentes, 
transformando profundamente a sociedade e a economia, fica claro a necessidade em capacitar um novo profissional, que saiba buscar conhecimentos e técnicas fundamentais necessárias para o acesso às informações, independentemente do ambiente e suporte em que as mesmas se encontrem.

\section{PERFIL DO MODERNO PROFISSIONAL DA INFORMAÇÃO}

A globalização da informação está mudando o perfil de muitos profissionais. Algumas profissões terão que, necessariamente, se adaptar ao mercado. A informação está ocupando um grande espaço no mundo do conhecimento e a cada minuto está sendo disponibilizada na rede global - a Internet, permitindo o acesso a diferentes pontos do planeta (BARROS, 1997).

Para Mueller (1989, p. 63), perfil profissional é o "conjunto de conhecimentos, qualidades $e$ competências próprias dos integrantes de uma profissão". Observa-se portanto, que este conceito está relacionado com a função profissional, delineando as habilidades e atitudes necessárias para o desempenho da mesma.

O profissional da informação assim como se denomina na pós-modernidade os profissionais com formação em Biblioteconomia, Documentação e Ciência da Informação, face as rápidas transformações de natureza tecnológica, social e econômica, deve estar preparado para atuar num contexto social e mercado de trabalho local, nacional e regional, sem esquecer o aqui e agora, mas, com vistas a este novo milênio, aberto às inovações tecnológicas e às oportunidades emergentes de trabalho.

Face a este contexto, o perfil do bibliotecário não pode mais limitar-se ao livro e a biblioteca. Sem perder de vista este suporte que é o âmago da profissão, deve estar preparado para tratar e disseminar a informação e conhecimento em qualquer suporte físico em que esteja registrado, seja este uma publicação impressa, microfilmada, audiovisual ou eletrônica. Conforme Guimarães (1997, p. 126), "novos mercados profissionais surgem. Se antes a atividade do bibliotecário podia ficar restrita aos limites fisicos de uma biblioteca e de uma coleção, agora o uso difundido da tecnologia a serviço da informação transpõe barreiras físicas e institucionais".

Preocupados com o perfil profissional exigido pelo mercado de trabalho, a ALA - American Library Association, em 1992, afirmou que o caráter essencial da Biblioteconomia e Ciência da Informação volta-se para a informação e o conhecimento registrado ou registrável, bem como para os serviços e tecnologias para habilitar sua gestão e uso, abrangendo a criação, a comunicação, identificação, seleção, aquisição, organização e descrição, armazenagem e recuperação, preservação, análise, interpretação, avaliação, síntese, disseminação e gestão da informação e do conhecimento.

Para a Special Libraries Association (1996), as competências do profissional bibliotecário devem contemplar:

- "Possuir conhecimento especializado dos recursos informacionais nos contextos interno e externo, com a competência para avaliar criticamente sua seleção;

- Possuir conhecimento especializado do "negócio" de sua instituição e dos clientes;

- Desenvolver e gerenciar serviços de informação eficazes a custos que se alinhem com as estratégias da organização;

- Oferecer apoio e treinamento adequado para usuários;

- Avaliar necessidades de informação, projetar e comercializar serviços de informação com valor agregado para satisfazer demandas identificadas;

- Utilizar as tecnologias da informação apropriadas na aquisição, tratamento e disseminação da informação;

- Utilizar abordagens gerenciais adequadas para promover a importância de serviços de informação junto às autoridades que tomam decisões;

- Desenvolver produtos de informação especializados para uso interno ou externo à instituição, por clientes individuais (desen- 
volver bases de dados, home-pages, arquivos de texto integral etc);

- Avaliar os resultados do uso da informação e liderar estudos relativos à solução dos problemas de gestão de produtos e serviços;

- Aprimorar continuamente os serviços de informação em função de novas exigências e desafios;

- Ser membro participante da equipe gerencial e um consultor da instituição em assuntos da área de informação."

Posteriormente, em 1994, representantes de inúmeras organizações não governamentais da área de Biblioteconomia e afins, reuniram-se em Tóquio, por ocasião das comemorações do centenário da International Federation and Documentation (FID). $\mathrm{Na}$ oportunidade foi assinada a Resolução de Tokyo, estabelecendo que o objetivo comum do profissional da informação é servir à sociedade. Nesta reunião foram levantadas ainda, as habilidades, atitudes e conhecimentos que o bibliotecário deve apresentar em seu perfil profissional (SANTOS, 1996).

Ainda na década de 90, a FID - Federação Internacional de Informação e Documentação, criou o Grupo SIG/MIP - Special Interest Group/Modern Information Profesional - MIP. O termo MIP, surgiu para atender a uma necessidade das unidades de informação, que trabalham hoje, principalmente com a realidade das novas tecnologias, contexto para o qual este profissional deve apresentar características como: flexibilidade, inovação, imaginação e criatividade. $\mathrm{O}$ MIP deve ser capaz de atender às exigências do mercado e proporcionar à sociedade serviços e suportes de informação adequados ao seu desenvolvimento e aprimoramento. A especialização e a educação continuada são requisitos básicos para o profissional da informação adquirir habilidades e conhecimentos para sua área de atuação. No Brasil, percebe-se a preocupação com o Moderno Profissional da Informação, sendo o mesmo tema de eventos da área, tema de projetos de pesquisa, disciplina nos cursos de graduação em Biblioteconomia e principalmente, pelo volume de trabalhos publicados na literatura, desta- cando-se neste momento, algumas ações que estão sendo desenvolvidas.

Em 1998 a Associação Brasileira de Ensino de Biblioteconomia e Documentação - ABEBD, preocupada com a formação do profissional da informação, realizou uma pesquisa com os 31 cursos de Biblioteconomia do Brasil (ABEBD, 1998). Na Região Sul os dados foram coletados a partir do formulário elaborado pela referida Associação e enviado aos seis cursos de Biblioteconomia: UDESC, UFSC, UEL, UFPR, UFRGS, FURG. Esta pesquisa revelou que o Perfil almejado pelos Cursos de Biblioteconomia da Região Sul deve levar o profissional a desenvolver as seguintes características (MAIA \& OHIRA, 1998, p. 30):

- "Atualizado;

- Criativo;

- Com atuação Interdisciplinar;

- Empreendedor;

- Ético;

- Fluente em sua própria língua;

- Inovador;

- Orientador ao usuário;

- Proativo;

- Preocupado com os fins."

Em Santa Catarina, a pesquisa de Bandeira (1999), realizada com os bibliotecários em exercício, levantou a opinião dos mesmos, sobre quais os conhecimentos, habilidades e atitudes que devem ser atribuídas ao Moderno Profissional da Informação, visando acompanhar as exigências impostas pelo mercado de trabalho. Como resultados, foram apontadas as seguintes características: ter paciência; agilidade, rapidez e simpatia, liderança e inteligência, flexibilidade, ser comunicativo, dinamismo, organização, atualização, boa memória, persistência e acima de tudo, gostar da profissão.

Como estudo mais recente, menciona-se Tarapanoff (2000), que aponta as novas tendências para o profissional da informação nas bibliotecas univer- 
sitárias, e que podem ser estendidas aos profissionais que atuam nas demais unidades de informação, mencionando ainda, que habilidades deve possuir para o desempenho desses novos/ velhos papéis:

- "Preservar a informação (ser responsável pela memória e cultura da produção técnica e científica local e institucional);

- Organizar a informação para uso;

- Acessar a informação. Conectar-se a redes, participar de consórcios e variadas formas de cooperação. Planejar a informação;

- Ser empreendedor, personalizar/customizar a informação. Ser consultor e infoempresário. Teletrabalho;

- Trabalhar a informação, agregar valor;

- Socializar a informação - preocupar-se com o acesso público à informação, a informação como um patrimônio público;

- Educar para a utilização da informação e para a sociedade da informação;

- Valorizar o conceito econômico da informação, participar do e-commerce, oferecendo serviços e produtos exclusivos;

- Criar, pesquisar e consumir informação."

Percebe-se claramente que estamos vivenciando uma fase de mudanças significativas em todos os aspectos da sociedade. Os perfis dos profissionais estão em constante processo de mudança, em função das tecnologias emergentes. Valores e paradigmas estão sendo quebrados a uma velocidade cada vez maior. A mudança do paradigma do acervo para a informação força o bibliotecário a desviar sua atenção do meio físico (documento) para seu objeto (a informação).

Tarapanoff (1997), discute os novos paradigmas que envolvem o fazer do profissional da informação, destacando-se os seguintes:

- "Paradigma Tecnológico;

- Paradigma da Biblioteca Virtual;

- Paradigma do Acesso à Informação;

- Paradigma da Qualidade e;

- Paradigma da Cooperação."
Para Guimarães (1997), a mudança de paradigma ocorreu gradativamente, como conseqüência das mudanças mundiais e acredita que de certa forma o perfil do MIP deve ser considerado como: uma "evolução", uma adequação de um perfil profissional a um mundo em mudança (...) Passou-se a exigir do profissional um "jogo de cintura" (adaptabilidade) que (...) pode-se concretizar por meio de visão gerencial, acurado poder de análise, criatividade e constante atualização.

Portanto, a formação do profissional bibliotecário deve estar pautada no paradigma da informação. A formação do profissional bibliotecário, no caso brasileiro, segundo Beraquet \& Valentim (s.d), "passou por fases técnicas e humanistas. Atualmente a estrutura dos cursos de biblioteconomia estão, na sua maioria, direcionados para esse paradigma, o da informação, buscando um profissional dinâmico $e$ competitivo que de fato atenda os anseios da sociedade brasileira".

\section{ESTUDOS DE COMPATIBILIZAÇÃO CURRICULAR}

De 1993 a 1996 a Associação Brasileira de Ensino de Biblioteconomia e Documentação $\mathrm{ABEBD}$, realizou vários eventos relativos aos estudos curriculares, em nível regional e nacional, com ênfase em estudos específicos sobre o currículo de biblioteconomia implantado no Brasil na década de 80 .

Em setembro de 1996, realizou-se em Porto Alegre o primeiro Encontro de Dirigentes de Escolas de Biblioteconomia do Mercosul, que contou com representantes do Uruguai, Paraguai, Argentina e Chile (como possível parceiro). Esse evento, além de propiciar um mútuo conhecimento das Escolas, pela primeira vez levantou perspectivas para harmonização curricular. Dessa forma, identificaram-se seis grandes áreas de conteúdo:

1. Fundamentos de Biblioteconomia e Ciência da Informação.

2. Gerência da Unidades de Informação.

3. Recursos e Serviços de Informação. 
4. Processamento da Informação.

5. Tecnologia da Informação.

6. Pesquisa.

Em continuidade, realizou-se em Buenos Aires, em novembro de 1997, o segundo Encontro de Diretores dos Cursos Superiores de Biblioteconomia do Mercosul, onde participaram os quatro países membros - Argentina, Brasil, Paraguai e Uruguai-e o Chile (como provável país a ser incluído), onde os docentes, reunidos por especialidades, chegaram a ementas básicas para o conteúdo de cada uma das seis grandes áreas.

No terceiro Encontro realizado em Santiago do Chile em outubro de 1998, novamente reuniram-se docentes por áreas visando aprofundar as discussões específicas de cada área temática, quando foram definidos o objetivo geral, os objetivos específicos, complementado com o peso específico e carga horária de cada área, dentro do currículo, conforme quadro abaixo.

Quadro 1. Distribuição das áreas e respectivo peso em \%

\begin{tabular}{|l|c|}
\hline \multicolumn{1}{|c|}{ Área } & $\begin{array}{c}\text { Peso } \\
\text { Específico }\end{array}$ \\
\hline 1. Fundamentos Teóricos da Biblioteconomia & $14 \%$ \\
\hline 2. Organização e Tratamento da Informação & $20 \%$ \\
\hline 3. Recursos e Serviços de Informação & $20 \%$ \\
\hline 4. Tecnologia da Informação & $16 \%$ \\
\hline 5. Gestão de Unidades e Serviços de Informação & $20 \%$ \\
\hline 6. Pesquisa & $10 \%$ \\
\hline
\end{tabular}

Paralelamente, no Brasil, a partir da nova Lei de Diretrizes e Bases da Educação - LDB, aprovada no segundo semestre de 1996, desencadeou-se o processo para definição das Diretrizes Curriculares para os Cursos de Biblioteconomia. As propostas resultantes dos estudos de compatibilização curricular do Mercosul, foram enviadas pela $\mathrm{ABEBD}$, à Comissão de Especialistas do MEC/SESu para que fossem analisadas e incorporadas a nova proposta de Diretrizes Curriculares.
A proposta do MEC de Diretrizes Curriculares para os Cursos de Biblioteconomia sugere o Perfil do Egresso e apresenta as competências e habilidades dos graduados em Biblioteconomia, subdivididas em: de caráter geral e comum e de caráter específico. O mesmo documento ainda apresenta os conteúdos dos cursos, conforme Quadro 2, que distribuem-se em matérias de formação geral, destinadas a oferecer referências cardeais externas aos campos de conhecimento próprios da Biblioteconomia e em matérias de formação específica, que são nucleares em relação cada uma das identidades profissionais em pauta. (BRASIL.MEC, 2000)

Quadro 2. Distribuição das matérias e respectivo conteúdo

\begin{tabular}{|l|l|}
\hline \multicolumn{1}{|c|}{ Matérias } & \\
\hline $\begin{array}{l}\text { Matérias de } \\
\text { formação geral }\end{array}$ & $\begin{array}{l}\text { Envolvem elementos teóricos e práticos e têm } \\
\text { por objetivo o melhor aproveitamento dos } \\
\text { conteúdos especificos de cada curso. De } \\
\text { acordo com o perfil acadêmico, estabelecer } \\
\text { um elenco variável de conhecimentos de } \\
\text { fundamentação como: Administração, } \\
\text { Antropologia, Comunicação, Direito, } \\
\text { Filosofia, História, Lingüistica, Sociologia } \\
\text { etc) indicando os elementos que justifiquem o } \\
\text { viés instrumental que assumem no currículo. }\end{array}$ \\
\hline $\begin{array}{l}\text { Matérias de } \\
\text { formação } \\
\text { específica }\end{array}$ & $\begin{array}{l}\text { - Fundamentos Teóricos da Biblioteconomia } \\
\text { - Organização e Tratamento da Informação } \\
\text { - Restão da Informação e do Conhecimento } \\
\text { - Tecnologias em Informação } \\
\text { - Políticas e Gestão de Unidades e Serviços } \\
\text { de Informação } \\
\text { - Metodologia da Pesquisa }\end{array}$ \\
\hline
\end{tabular}

O referencial teórico discutido neste trabalho, subsidiou as discussões para a elaboração da proposta curricular do Curso de Biblioteconomia da UDESC, apresentada a seguir.

\section{ESTRUTURA CURRICULAR DO CURSO DE BIBLIOTECONOMIA - UDESC}

Considerando-se os estudos da literatura que abordam questões relacionadas com o Moderno Profissional da Informação, a Proposta de Harmonização Curricular do Mercosul desenvolvida pela 
$\mathrm{ABEBD}$ e as Diretrizes Curriculares do MEC, o Perfil do profissional bibliotecário para o Curso de Biblioteconomia - Habilitação em Gestão da Informação da Universidade do Estado de Santa Catarina - UDESC pretende-se:

"O egresso do curso de Biblioteconomia como gestor da informação estará apto a atuar crítica e tecnicamente na utilização dos recursos informacionais existentes em instituições e sistemas de informação, em âmbito local, regional, nacional e do MERCOSUL, visando a democratização da informação como meio de garantir o exercício da cidadania. Este profissional será capaz de utilizar as novas tecnologias como recurso na organização, armazenamento, acesso e uso da informação e do conhecimento."

Dentre as competências e habilidades dos graduados em Biblioteconomia, propostas pelas Diretrizes Curriculares do MEC, enumeram-se as de caráter geral e comum, típicas desse nível de formação e aquelas de caráter específico, das quais selecionamos as seguintes para o Perfil do Egresso do Curso de Biblioteconomia - Habilitação em Gestão da Informação, da Universidade do Estado de Santa Catarina - UDESC:

a. De caráter geral e comum:

- Articular elementos empíricos e conceituais com propriedade;

- Gerar produtos resultantes dos conhecimentos adquiridos;

- Desenvolver e aplicar instrumentos de trabalho adequados;

- Elaborar, coordenar, executar e avaliar planos, programas e projetos;

- Utilizar racionalmente os recursos disponíveis;

- Desenvolver e utilizar novas tecnologias;

- Traduzir as necessidades de indivíduos, grupos e comunidades nas respectivas áreas de atuação;

- Responder a demandas determinadas pelas transformações que caracterizam o mundo contemporâneo.

\section{b. De caráter específico:}

- Interagir e agregar valor nos processos de geração, transferência e uso da informação em todo e qualquer ambiente;

- Criticar, investigar, propor, planejar, executar e avaliar recursos e produtos de informação;

- Trabalhar com fontes de informação de qualquer natureza;

- Processar a informação registrada em diferentes tipos de suporte, mediante a aplicação de conhecimentos teóricos e práticos de coleta, processamento, armazenamento e difusão da informação;

- Realizar pesquisas relativas a produtos, processamento, transferência e uso da informação.

Tendo em vista que ainda encontram-se em estudo as Diretrizes Curriculares Brasileiras para a área de Ciência da Informação, que engloba os cursos de Biblioteconomia, Arquivologia e Museologia, a proposta de alteração curricular para o Curso de Biblioteconomia - Habilitação em Gestão da Informação da Universidade do Estado de Santa Catarina - UDESC atende as exigências legais para a estruturação curricular determinadas pelos seguintes documentos:

\section{Proposta de Diretrizes Curriculares para} os Cursos de Biblioteconomia do MEC, que estão em discussão no Conselho Nacional de Educação-CNE;

2. Resolução 08 de 29 de outubro de 1982, do Conselho Federal de Educação que estabelece as matérias para o currículo mínimo do Curso de Biblioteconomia, e

Por esta razão a proposta de alteração apresenta uma estrutura curricular que contempla as exigências legais dos documentos expostos acima.

Para atender as exigências das Diretrizes Curriculares do MEC, as disciplinas foram agrupadas em: Formação Geral e Formação Profissional Específica, onde deverão ser cursados 49 créditos nas matérias de Formação Geral e 138 créditos para área de Formação Profissional Específica, totalizando $\mathbf{1 8 7}$ créditos o que corresponde a $\mathbf{2 . 8 0 5}$ horas/aula. 
Quadro 3. Matérias de Formação Geral de acordo com as Diretrizes Curriculares do MEC

\begin{tabular}{|c|c|c|c|}
\hline Matérias & Disciplinas Propostas & CR & $\mathrm{CH}$ \\
\hline 1. Literatura & $\begin{array}{l}\text { 1.1. Leitura e Literatura Infanto-Juvenil } \\
\text { 1.2. Literatura de Língua Portuguesa } \\
\end{array}$ & $\begin{array}{l}03 \\
02 \\
\end{array}$ & $\begin{array}{l}45 \\
30 \\
\end{array}$ \\
\hline 2. Filosofia & $\begin{array}{l}\text { 2.1 Evolução do Pensamento Científico e Filosófico } \\
\text { 2.2 Lógica Aplicada à Documentação }\end{array}$ & $\begin{array}{l}03 \\
03 \\
\end{array}$ & $\begin{array}{l}45 \\
45 \\
\end{array}$ \\
\hline 3. Sociologia & 3.1 Sociologia Geral & 03 & 45 \\
\hline 4. Antropologia & 4.1 Antropologia Cultural & 04 & 60 \\
\hline 5. História & 5.1 História da Arte & 03 & 45 \\
\hline 6. Administração & $\begin{array}{l}\text { 6.1 Teorias Administrativas } \\
\text { 6.2 Organização \& Métodos (O\&M) } \\
\text { 6.3. Psicologia das Relaçбes do Trabalho }\end{array}$ & $\begin{array}{l}04 \\
03 \\
03 \\
\end{array}$ & $\begin{array}{l}60 \\
45 \\
45 \\
\end{array}$ \\
\hline 7. Comunicação & 7.1 Teoria da Comunicação & 02 & 30 \\
\hline 8. Ciência da Computação & $\begin{array}{l}\text { 8.1 Introdução à Informática } \\
\text { 8.2 Redes de Computadores } \\
\end{array}$ & $\begin{array}{l}02 \\
02 \\
\end{array}$ & $\begin{array}{l}30 \\
30 \\
\end{array}$ \\
\hline 9. Linguas Modernas & \begin{tabular}{|l} 
9.1 Inglês Instrumental \\
9.2. Espanhol Instrumental \\
\end{tabular} & $\begin{array}{l}04 \\
04 \\
\end{array}$ & $\begin{array}{l}60 \\
60 \\
\end{array}$ \\
\hline $\begin{array}{l}\text { Obrigatórias } \\
\text { 10. Educação Física }\end{array}$ & $\begin{array}{l}\text { 10.1. Educação Física Curricular I } \\
\text { 10.2. Educação Física Curricular II }\end{array}$ & $\begin{array}{l}02 \\
02 \\
\end{array}$ & $\begin{array}{l}30 \\
30 \\
\end{array}$ \\
\hline Total & & 49 & 735 \\
\hline
\end{tabular}

Quadro 4. Matérias de Formação Profissional Específica de acordo com as Diretrizes Curriculares do MEC

\begin{tabular}{|c|c|c|c|}
\hline Matérias & Disciplinas Propostas & CR & $\mathrm{CH}$ \\
\hline $\begin{array}{l}\text { I. Fundamentos Teóricos da } \\
\text { Biblioteconomia }\end{array}$ & $\begin{array}{l}\text { 1.1. Introdução à Ciência da Informação } \\
\text { 1.2. História do Livro e das Bibliotecas } \\
\text { 1.3. Fundamentos em Arquivologia }\end{array}$ & $\begin{array}{l}05 \\
04 \\
05\end{array}$ & $\begin{array}{l}75 \\
60 \\
75\end{array}$ \\
\hline $\begin{array}{l}\text { 2. Organização e Tratamento } \\
\text { da Informação }\end{array}$ & $\begin{array}{l}\text { 2.1. Representação Descritiva I } \\
\text { 2.2. Representação Descritiva II } \\
\text { 2.3. Representação Descritiva III } \\
\text { 2.4. Introdução ao Tratamento Temático da Informação } \\
\text { 2.5. Representação Temática I } \\
\text { 2.6. Representação Temática II } \\
\text { 2.7. Representação Temática III }\end{array}$ & $\begin{array}{l}05 \\
04 \\
03 \\
03 \\
04 \\
04 \\
04\end{array}$ & $\begin{array}{l}75 \\
60 \\
45 \\
45 \\
60 \\
60 \\
60\end{array}$ \\
\hline $\begin{array}{l}\text { 3ecursos e Serviços } \\
\text { de Informação }\end{array}$ & $\begin{array}{l}\text { 3.1 Serviço de Referência e Informação } \\
\text { 3.2. Fontes de Informação } \\
\text { 3.3. Recuperação da Informação } \\
\text { 3.4. Ação Cultural }\end{array}$ & $\begin{array}{l}04 \\
05 \\
03 \\
04\end{array}$ & $\begin{array}{l}60 \\
75 \\
45 \\
60 \\
\end{array}$ \\
\hline $\begin{array}{l}\text { 4. Gestão da Informação e } \\
\text { do Conhecimento }\end{array}$ & $\begin{array}{l}\text { 4.1 Gestão da Informação } \\
\text { 4.2 Tópicos Especiais em Gestão da Informação e do Conhecimento } \\
4.3 \text { Gestão de Estoques Informacionais }\end{array}$ & $\begin{array}{l}03 \\
03 \\
05\end{array}$ & $\begin{array}{l}45 \\
45 \\
75\end{array}$ \\
\hline 5. Tecnologia em Informação & $\begin{array}{l}\text { 5.1 Informática Documentária } \\
\text { 5.2 Planejamento e Geração de Bases de Dados } \\
\text { 5.3 Tecnologia da Informação Aplicada à Biblioteconomia }\end{array}$ & $\begin{array}{l}05 \\
03 \\
03 \\
\end{array}$ & $\begin{array}{l}75 \\
45 \\
45 \\
\end{array}$ \\
\hline $\begin{array}{l}\text { 6. Políticas e Gestão de Unidades } \\
\text { e Serviços de Informação }\end{array}$ & $\begin{array}{l}\text { 6.1 Administração de Unidades de Informação } \\
\text { 6.2 Planejamento de Unidades de Informação } \\
\text { 6.3 Usuários da Informação } \\
\text { 6.4. Estágio Curricular I } \\
\text { 6.5. Estágio Curricular II } \\
\end{array}$ & $\begin{array}{l}04 \\
04 \\
03 \\
10 \\
10\end{array}$ & $\begin{array}{c}60 \\
60 \\
45 \\
150 \\
150 \\
\end{array}$ \\
\hline 7. Metodologia da Pesquisa & $\begin{array}{l}\text { 7.1. Estatística } \\
\text { 7.2. Produção de Textos } \\
\text { 7.3. Métodos e Técnicas de Pesquisa } \\
\text { 7.4. Normalização da Documentação } \\
\text { 7.5. Projeto do TCC } \\
\text { 7.6. Elaboração do TCC } \\
\end{array}$ & $\begin{array}{l}04 \\
03 \\
04 \\
04 \\
03 \\
10\end{array}$ & $\begin{array}{c}60 \\
45 \\
60 \\
60 \\
45 \\
150\end{array}$ \\
\hline Total & & 138 & 2070 \\
\hline
\end{tabular}


Quadro 5. Total de créditos de acordo com as Diretrizes Curriculares do MEC

\begin{tabular}{|l|c|c|}
\hline $\begin{array}{c}\text { Quadro Geral } \\
\text { Total de Créditos Matérias }\end{array}$ & Créditos & CH \\
\hline Formação Geral & 49 & 735 \\
\hline Formação Profissional Especifica & 138 & 2070 \\
\hline Total & $\mathbf{1 8 7}$ & $\mathbf{2 . 8 0 5}$ \\
\hline
\end{tabular}

Para atender as exigências do Currículo Mínimo - Resolução N. 08, de outubro de 1982 do CFE as disciplinas foram agrupados em: Fundamentação Geral, Instrumentais, Formação Complementar Obrigatória, com o total de 70 créditos e Formação Profissional com 117 créditos, totalizando 187 créditos, o que corresponde a $\mathbf{2 . 8 0 5}$ horas/aula.

Quadro 6. Matérias de Fundamentação Geral - Resolução n. 08/1982

\begin{tabular}{|l|l|c|c|}
\hline \multicolumn{1}{|c|}{ Matérias } & \multicolumn{1}{|c|}{ Disciplinas Propostas } & CR & CH \\
\hline $\begin{array}{l}\text { 1. Aspectos Sociais, Políticose } \\
\text { Econômicos do Brasil } \\
\text { Contemporâneo }\end{array}$ & 1.1 Sociologia Geral & 03 & 45 \\
\hline 2. Comunicação & & 02 & 30 \\
\hline 3. História da Cultura & 2.1 Teoria da Comunicação & 04 & 60 \\
\hline Obrigatória & 3.1 Antropologia Cultural & 03 & 45 \\
4. Educação Física & 3.2 História da Arte & 02 & 30 \\
\hline
\end{tabular}

Quadro 7. Matérias Instrumentais - Resolução n. 08/1982

\begin{tabular}{|l|l|c|c|}
\hline \multicolumn{1}{|c|}{ Matérias } & \multicolumn{1}{|c|}{ Disciplinas Propostas } & CR & CH \\
\hline 1. Lingua Estrangeira Moderna & 1.1 Espanhol Instrumental & 04 & 60 \\
& 1.2 Inglês Instrumental & 04 & 60 \\
\hline 2. Lingua Portuguesa e Literaturas & 2.1 Literaturas de Língua Portuguesa & 02 & 30 \\
de Lingua Portuguesa & 2.2 Produção de Texto & 03 & 45 \\
\hline \multirow{2}{*}{ 3. Lógica } & 3.1 Evolução do Pensamento Cientifico e Filosófico & 03 & 45 \\
& 3.2 Lógica Aplicada à Documentação & 03 & 45 \\
\hline \multirow{2}{*}{ 4. Métodos e Técnicas de Pesquisa } & 4.1 Elaboração do TCC & 10 & 150 \\
& 4.2 Estatística & 04 & 60 \\
& 4.3 Métodos e Técnicas de Pesquisa & 04 & 60 \\
& 4.4 Normalização da Documentação & 04 & 60 \\
& 4.5 Projeto TCC & 03 & 45 \\
\hline
\end{tabular}

Quadro 8. Matérias de Formação Complementar Obrigatória - Resolução n. 08/1982

\begin{tabular}{|l|l|c|c|}
\hline & \multicolumn{1}{|c|}{ Disciplinas } & CR & CH \\
\hline & 1. Introdução à Informática & 02 & 30 \\
\hline & 2. Leitura e Literatura Infanto-Juvenil & 03 & 45 \\
\hline & 3. Psicologia das Relações do Trabalho & 03 & 45 \\
\hline & 4. Redes de Computadores & 02 & 30 \\
\hline
\end{tabular}


Quadro 9. Matérias de Formação Profissional - Resolução n. 08/1982

\begin{tabular}{|c|c|c|c|}
\hline Matérias & Disciplinas Propostas & CR & CH \\
\hline 1. Administração de Bibliotecas & $\begin{array}{l}\text { 1.1. Administração de Unidades de Informação } \\
\text { 1.2. Gestão da Informação } \\
\text { 1.3. O \& M } \\
\text { 1.4. Planejamento de Unidades de Informação } \\
\text { 1.5. Planejamento e Geração de Base de Dados } \\
\text { 1.6. Estágio Curricular I } \\
\text { 1.7. Estágio Curricular II } \\
\text { 1.8. Teorias Administrativas }\end{array}$ & $\begin{array}{l}04 \\
03 \\
03 \\
04 \\
03 \\
10 \\
10 \\
04\end{array}$ & $\begin{array}{l}60 \\
45 \\
45 \\
60 \\
45 \\
150 \\
150 \\
60 \\
\end{array}$ \\
\hline $\begin{array}{l}\text { 2. Controle Bibliográfico dos } \\
\text { Registros do Conhecimento }\end{array}$ & $\begin{array}{l}\text { 2.1. Fundamentos em Arquivologia } \\
\text { 2.1. Introdução ao Tratamento Temático da Informação } \\
\text { 2.3. Representação Descritiva I } \\
\text { 2.4. Representação Descritiva II } \\
\text { 2.5. Representação Descritiva III } \\
\text { 2.6. Representação Temática I } \\
\text { 2.7. Representação Temática II } \\
\text { 2.8. Representação Temática III }\end{array}$ & $\begin{array}{l}05 \\
03 \\
05 \\
04 \\
03 \\
04 \\
04 \\
04 \\
\end{array}$ & $\begin{array}{l}75 \\
45 \\
75 \\
60 \\
45 \\
60 \\
60 \\
60\end{array}$ \\
\hline 3. Disseminação da Informação & $\begin{array}{l}\text { 3.1. Ação Cultural } \\
\text { 3.2. Recuperação da Informação } \\
\text { 3.3. Fontes de Informação } \\
\text { 3.4. Serviço de Referência e Informação } \\
\text { 3.5. Usuários da Informação }\end{array}$ & $\begin{array}{l}04 \\
03 \\
05 \\
04 \\
03\end{array}$ & $\begin{array}{l}60 \\
45 \\
75 \\
60 \\
45\end{array}$ \\
\hline $\begin{array}{l}\text { 4. Formação e Desenvolvimento de } \\
\text { Coleções }\end{array}$ & 4.1 Gestão de Estoques Informacionais & 05 & 75 \\
\hline $\begin{array}{l}\text { 5. Informação Aplicada à } \\
\text { Biblioteconomia }\end{array}$ & $\begin{array}{l}\text { 5.1 Informática Documentária } \\
\text { 5.2 Introdução à Ciência da Informação } \\
\text { 5.3 Tecnologia da Informação Aplicada à Biblioteconomia } \\
\text { 5.4. Tópicos Especiais em Gestão da Informação e do Conhecimento } \\
\end{array}$ & $\begin{array}{l}05 \\
05 \\
03 \\
03 \\
\end{array}$ & $\begin{array}{l}75 \\
75 \\
45 \\
45 \\
\end{array}$ \\
\hline $\begin{array}{l}\text { 6. Produção dos Registros do } \\
\text { Conhecimento }\end{array}$ & 6.1 História do Livro e das Bibliotecas & 04 & 60 \\
\hline
\end{tabular}

Quadro 10. Total de créditos de acordo com a Resolução n. 08/1982

\begin{tabular}{|l|c|c|}
\hline \multicolumn{1}{|c|}{$\begin{array}{c}\text { Quadro Geral } \\
\text { Total de Créditos Matérias }\end{array}$} & Créditos & CH \\
\hline $\begin{array}{l}\text { Fundamentação Geral, Instrumentais e } \\
\text { Formação Complementar Obrigatória }\end{array}$ & 70 & 1.050 \\
\hline Formação Profissional & 117 & 1.755 \\
\hline Total & $\mathbf{1 8 7}$ & $\mathbf{2 . 8 0 5}$ \\
\hline
\end{tabular}

Como resultado, o Curso está estruturado em 8 (oito) fases, com o mesmo elenco de disciplinas, atendendo assim a Resolução 08/82 do Currículo Mínimo, e a Proposta de Diretrizes Curriculares do MEC, com um total de 187 créditos, o que corresponde a 2805 horas/aula. Neste total estão incluídos 4 créditos $=60$ horas/aula para as disciplinas obrigatórias (Educação Física Curricular), 20 créditos para Estágio Curricular, o que corresponde o total de 300 horas e 13 créditos para elaboração do Trabalho de Conclusão de Curso - TCC, que corresponde a 195 horas/aula.

O Estágio Curricular será desenvolvido em duas disciplinas: Estágio Curricular I - na $6^{\mathrm{a}}$ fase e Estágio Curricular II - na $7^{\mathrm{a}}$ fase com a apresentação dos respectivos relatórios. Em ambas disciplinas, o aluno fará um diagnóstico da Unidade de Informação para levantamentos dos recursos existentes, e realizará um treinamento supervisionado com o objetivo de desenvolver habilidades e colocar em prática os conhecimentos teóricos adquiridos durante o Curso. Ressalta-se que na disciplina Estágio Curricular I (10 créditos), a ênfase será para atividades relacionadas com a gestão, organização e tratamento do acervo e na disciplina Estágio Curri- 
cular II (10 créditos), a ênfase será para as atividades relacionadas com a Gestão, acesso e uso da informação, ambos, sob a orientação de um professor do Curso de Biblioteconomia.

O Trabalho de Conclusão de Curso (TCC), terá início na $7^{\mathrm{a}}$ fase, para o qual foram destinados 3 créditos. A conclusão das disciplinas de Formação Geral, das Disciplinas Profissionalizantes e a conclusão dos Estágios Curriculares I e II, permitirão que o aluno eleja um tema de sua preferência e o aprofunde por meio de um trabalho de investigação a ser desenvolvido na $8^{\mathrm{a}}$ fase, sendo destinado para o mesmo um total de 10 créditos, sob a orientação de um professor do Curso de Biblioteconomia. A avaliação do TCC será feita pelo orientador e por um docente do Colegiado de Curso de Biblioteconomia. A indicação de profissionais que atuam em Unidades de Informação e/ou professores de outros cursos, departamentos e universidades, como avaliadores do TCC, deverá ser apreciado pelo Colegiado de Curso. O TCC deverá ser apresentado no Seminário de Estágio que consta do calendário acadêmico do Centro de Ciências da Educação.

De acordo com a legislação vigente, o Curso de Biblioteconomia - Habilitação em Gestão da Informação da UDESC, deverá ser integralizado no mínimo em 3 anos e meio e no máximo em sete anos. A presente alteração curricular entrou em vigor a partir de 2001/1.

\section{REFERÊNCIAS BIBLIOGRÁFICAS}

ASSOCIAÇÃO BRASILEIRA DE ENSINO DE BIBLIOTECONOMIA, DOCUMENTAÇÃO E CIÊNCIA DA INFORMAÇÃO. Moderno Profissional da Informação: o perfil almejado pelos cursos de Biblioteconomia brasileiros. Porto Alegre: ABEBD, 1998. (Documentos ABEBD, 13)

BANDEIRA, Gabrielle Pereira. Quem é o bibliotecário em exercício no Estado de Santa Catarina: mercado de trabalho. Florianópolis, 1999. Monografia (Curso de Especialização em Estratégias e Qualidade em Sistemas de Informação) - Curso de Biblioteconomia, Universidade do Estado de Santa Catarina.
BARROS, Lucivaldo Barros Vasconcellos. O perfil do bibliotecário no advir do terceiro milênio: o novo profissional face às exigências do mercado de trabalho. In: CONGRESSO BRASILEIRO DE BIBLIOTECONOMIA E DOCUMENTAÇÃO, 18, 1997. São Luís. Anais eletrônicos... [disquetes] São Luís, 1997.

BRASIL. Ministério de Educação e Cultura. Proposta de Diretrizes Curriculares para os cursos de Biblioteconomia. Disponível em: http://www.mec.br/

BERAQUET, Vera Silvia Marão; VALENTIM, Marta Lígia Pomim. Competências exigidas do profissional da informação e novas estratégias de formação. (s.d.)

EGGERT, Gisela; OLIVEIRA, Sueli Ferreira Júlio de; SCHIMIEGELOW, Karla. As bibliotecas públicas municipais do Estado de Santa Catarina: agências de informação, conhecimento - realidades e possibilidades. (Relatório do Projeto de Pesquisa do Programa de Iniciação Científica do CNPq)

GUIMARÃes, José Augusto Chaves. Moderno profissional da informação: elementos para sua formação no Brasil. Transinformação, Campinas, v. 9, n. 1, pp.124-137, jan./abr. 1997.

MAIA, Maria Helena Bier; OHIRA, Maria Lourdes Blatt. Perfil do profissional da informação almejado pelos cursos de Biblioteconomia da região sul do Brasil. Porto Alegre: UFRGS, 1998 pp. 3-35. (Cadernos ABEBD, 13)

MUELler, Suzana Pinheiro Machado. Perfil do bibliotecário, serviços e responsabilidades na área de informação e formação profissional. Revista da Escola de Biblioteconomia de Brasília, v. 17, n. 1, pp. 63-70, jan./jun. 1989.

OHIRA, Maria Lourdes Blatt; MAIA, Maria Helena Bier, SELL, Maria Aparecida. Produção científica em Biblioteconomia no Estado de Santa Catarina. Transinformação, Campinas, v. 9, n. 3, pp. 68-87, set./dez. 1997.

PROSDÓCIMO, Zulma Pures Alves. Quem é o bibliotecário em exercício no Estado de Santa Catarina: necessidades de educação continuada. Florianópolis, 1999. Monografia (Curso de Especialização em estratégias e Qualidade em Sistemas de Informação) - Curso de Biblioteconomia, Universidade do Estado de Santa Catarina.

SANTOS, Jussara Pereira. O moderno profissional da informação: o bibliotecário e seu papel face aos novos tempos. Informação \& Informação, Londrina, v. 1, n. 1, pp. 5-13, jan./jun. 1996. 
SPECIAL LIBRARIES ASSOCIATION. Competências para os bibliotecários do século 21. 1996. Disponível em http://www.fgv.br/diti/bib/geral/Acesso em 18, out. 2000.

TARAPANOFF, Kira. Perfil do profissional da informação no Brasil. Brasília: IEL/DF, 1997.
TARAPANOFF, Kira. As novas tendências e o profissional da informação nas Bibliotecas Universitárias do século XXI. Florianópolis: SNBU, 2000 (Trabalho apresentado no XI Seminário Nacional de Bibliotecas Universitárias, Florianópolis, 2000) 